\title{
Controlled Clinical Trial on Effect of 'Carica Papaya' Leaf Extract on Patients with Dengue Fever
}

Sanath Hettige ${ }^{1,2 *}$, Jagath Pushpakumara ${ }^{3,4}$, Lagath Udara Wanigabadu ${ }^{5}$, Eliyapurage Minaka Ransirini Hettige ${ }^{6}$, Arosha Kottege ${ }^{4}$ Jayaratne $\mathrm{SD}^{4,7}$ and Gunathilake Saman ${ }^{4,7}$

${ }^{1}$ Faculty of Medicine, University of Colombo, Sri Lanka

${ }^{2}$ Post Graduate Institute of Medicine, University of Colombo Sri Lanka

${ }^{3}$ Basingstoke and North Hampshire Hospital, Basingstoke, UK

${ }^{4}$ University Medical Unit, Colombo South Teaching Hospital, Kalubowila, Sri Lanka

${ }^{5}$ Royal Bournemouth Hospital, Bournemouth, UK

${ }^{6}$ Sri Jayewardenepura General Hospital, Nugegoda, Sri Lanka

${ }^{7}$ Faculty of Medical Sciences, University of Sri Jayawardenapura, Sri Lanka

${ }^{*}$ Corresponding author: Dr. Sanath Hettige, Address: 92, Wattegedara Road, Maharagama, Sri Lanka; Tel: +94112851517, +94772283730; Email: hettiges@sltnet. lk, sanathhettige@gmail.com

Received: June 14, 2020; Accepted: June 22, 2020; Published: June 24, 2020

\begin{abstract}
Background: Dengue is a mosquito-borne infection, which in recent decades has become a major international public health concern. Dengue is found in tropical and sub-tropical regions around the world, predominantly in urban and semi-urban areas with high morbidity and mortality rates.

Up to now there is no safe and effective vaccine or therapeutic agent available for Dengue fever. Carica papaya leaf extract is the only therapeutic agent used for its platelet rising properties. In this study we are looking at other therapeutic benefits.
\end{abstract}

Aim: To compare the clinical, haematological and biochemical profiles of dengue patients treated with and without oral Carica papaya leaf extracts.

Design \& Setting: Open label randomized controlled clinical trial in a Teaching Hospital in Sri Lanka.

Method: 161 Dengue suspected patients. Treatment group was given to drink leaf extract daily until discharged. Control group was not given the extract. Both groups were managed according to national dengue guidelines.

Results: 161 patients were randomized (77 treatment group and 84 control group). After exclusions, 43 patients who consumed leaf extract and 76 controls were taken for analysis.

Mean duration of fever in hospital was 1.13 days less in treatment group $1.67 \pm 1.36$ vs. $2.8 \pm 1.79$ ( $\mathrm{p}<0.001)$.

Mean duration of the illness was 0.5 days less in treatment group $6.51 \pm 1.05$ vs. $6.96 \pm 1.32(\mathrm{p}<0.05)$.

Mean duration of hospital stay was 0.78 day less in treatment group $3.69 \pm 1.08$ vs. $4.47 \pm 1.40$ ( $\mathrm{p}<0.001)$.

Leading to dengue haemorrhagic fever was significantly reduced ( $p$ value $<0.05$ ) in treatment group (Proportion Normality test, $p$ value 0.000 ).

Conclusion: Papaya leaf extracts has significantly reduced the duration of fever, illness, hospital stay and the incidence of conversion to dengue hemorrhagic fever.

Keywords: Carica papaya, Dengue, Dengue hemorrhagic fever, Pleural effusion, Duration of illness, Platelet count

\section{Introduction}

\section{Background}

Dengue is a mosquito-borne infection, which in recent decades has become a major international public health concern. Approximately half of the world now lives under the threat of Dengue, which is responsible for approximately 390 million infections and 20,000 deaths globally each year. Decades of attempt to eradicate dengue have not being successful at any part of the world. Up to now there is no safe and effective vaccine or therapeutic agent available [1]. Carica papaya leaf extract (CPLE) is the only therapeutic agent that has been used for its platelet rising properties [2,3].

Carica papaya (Family Caricaceae) originated in Central America. The papaya is an extraordinarily useful plant. In the tropics of the world, ripe papaya fruit is consumed as a breakfast fruit. Its juice is a popular beverage. The leaves and young stems are steamed and served as a vegetable. In some Asian countries, young leaves of papaya are steamed and eaten like spinach. Yet in other countries papaya leaves are brewed as tea and taken as a preventative measure against Malaria $[4,5]$. Monkeys and peacocks consumes papaya leaf at will when they 
enter a papaya plantation. All this points to the fact that it's not toxic for human consumption.

Salutary Effects of CPLE in Dengue Fever (DF) patients was published in 2008 edition of the Journal of Sri Lanka Family Physicians [6]. This is most likely to be the first ever scientific biomedical study conducted to discover the salutary effects of CPLE in patients suffering from $\mathrm{DF}$, reported in the world literature.

Following this study many research have been done including Randomized Controlled clinical Trials (RCT) and toxicology studies [7-24]. All have shown beneficial effects with no major adverse effects. In this study we have also looked at other therapeutic benefits, which have not been looked at before like its effects on the duration of fever, illness and most importantly prevention of conversion of DF to Dengue haemorrhagic fever (DHF).

The first contact in DF is Primary Care physicians. If an effective therapeutic agent could be given at this first consultation, it can lead to reduction in morbidity and mortality. CPLE is a potential therapeutic agent, which need further research $[3,8]$.

\section{Objectives}

The main objective of this study is to compare the clinical (Duration of Hospital stay, Duration of fever, Plural Effusion/ percentage of conversion to DHF), Haematological (White cell count (WBC), Packed cell volume (PCV) Platelet count (PLT) and Biochemical parameters (Alanine transaminase (SGPT), Aspartate transaminase (SGOT) ) of dengue patients treated with and without oral CPLE.

\section{Methods}

\section{Trial Design}

Open labelled Randomized Controlled clinical Trial.

Patients fulfilling the inclusion criteria were randomly allocated to the treatment and control groups.

\section{Participants}

Patients admitted to University medical unit full filling the following inclusion criteria war eligible for the study.

Inclusion criteria were acute onset of fever, 18 to 60 years of age, with a platelet count $<150,000$ per cu.mm and white cell count $<5000$ per cu.mm or with a positive dengue NS1 antigen test who wear in the febrile phase of illness and not developed DHF.

All subjects in both groups were confirmed as dengue by IgM positive after 7 days of fever. Subjects who were IgM negative after 7 days were excluded.

Exclusion criteria were patients who are in critical phase with DHF, history of allergy to papaya, pregnant mothers, patients who have already taken papaya juice extracts before admitting to hospital, patients with previously diagnosed abnormal clotting profile as per past history and medical records, patients suffering from any other illnesses which will influence the course of dengue fever, patients suffering from any other illnesses or on drugs which will influence the bone marrow function or haemopoitic system, dengue patients who have been treated with blood products.

Eligible subjects were randomly allocated to treatment and control groups Subjects were recruited until the required numbers of participants were achieved.

\section{Study Setting}

Study was conducted at University medical unit at Colombo South Teaching Hospital, Kalubowila, Sri Lanka. It is a tertiary care hospital in an urban setting where patients can present themselves to OPD on their own or referred by a family doctor or by other medical institutions.

Written Informed consent was obtained from all the patients included in the study. Patients who gave consent to take part in the study were randomized equally to treatment group and control group.

\section{Interventions}

The Treatment group was given oral CPLE, $20 \mathrm{ml} 12$ hourly daily till the patient was fit to be discharged. Both groups was managed according to national guidelines in dengue $[25,26]$.

CPLE was prepared by obtaining mature papaya leafs from previously identified and tested red lady variety papaya plantation. $100 \mathrm{~g}$ of leaves was cut into small pieces and grinded in a grinding machine till you get a uniform pulp. This pulp was put to a juice extract to obtain the pure extract. To $50 \mathrm{ml}$ of this extract, $50 \mathrm{ml}$ of cool boiled water was added and mixed well.

Initial preparation and subsequent preparations were assessed and standardized using high performance liquid chromatography. $20 \mathrm{ml}$ of this preparation was packed in sterile glass bottles and stored in refrigerator at $4^{\circ} \mathrm{C}$ before giving it to the patient.

\section{Primary Outcome}

Immediately after admission and daily till discharge, a $10 \mathrm{ml}$ sample of blood was withdrawn by venepuncture in both groups for the determination of WBC, PLT, PCV, SGPT and SGOT.

Both groups were examined daily by the ward registrar and the senior house officer and fever, haematological and biochemical parameters were entered in the data collecting forms. In ward ultrasound scans were done to detect pleural effusion by the ward registrar who had been trained in this procedure before the commencement of the study. Pleural effusion was taken as an indicator for plasma leakage and DHF [25].

Patients in both groups were discharged according to the same criteria as given in the national guidelines of dengue fever management [26]. The discharge criteria were absence of fever with improvement of all other clinical and biochemical parameters including the absence of leakage and rise in the PLT. The dissection to discharge was made by chief consultant in charge of the unit who did not know whether the patient was in the treatment group or the control group.

\section{Sample Size}

Platelet counts were considered for sample size calculation [27]. 
Approximate standard deviation $=($ Highest typical value-Lowest typical value) $/ 4$

$=\left(400,000-150,000^{28}\right) / 4$

$=62,500$

= Minimum difference to be detected for a significant difference/ standard deviation $=50,000 / 62,500$

$=0.8$

$\mathrm{N}=41$ for each group with $95 \%$ power

\section{Randomization}

The patients who gave consent to take part in the study was randomly allocated to treatment group and control group by the medical registrars attached to the ward by a concealed method. This randomization was done by asking the patient to pick up a tag concealed in an envelope (labelled as treatment or control) from a box, which was not transparent.

\section{Statistical Methods}

Collected data were analyzed using the Shapiro-Wilk test to assess the normality of the data and it showed that $p$ values of all the variables are less than 0.05 and the data are not normal. Mann Whitney $U$ test (Non parametric test) had been used to assess the significance.

\section{Trial Registration}

Sri Lanka Clinical Trial Registry.

\section{SLCTR/2013/005}

\section{Results}

Hundred and sixty one $(\mathrm{n}=161)$ patients entered the study and randomized into two groups (77 patients in the treatment group and 84 patients in the control group). Thirty-four patients were excluded from the treatment group (Sample rejected at the onset $n=13$, Bitter induce vomiting $=02$, Data Incomplete $n=01$ Dengue $\operatorname{IgM}$ negative $\mathrm{n}=18$ ). Eight patients were excluded from the control group (IgM negative $\mathrm{N}=8$ ) (Figure 1).

After exclusion, treatment group was 43 patients and the control 76 patients. 43 patients who consumed CPLE and 76 controls were taken for analysis.

The number of Controls $(\mathrm{n}=76)$ were higher than the Treatment group ( $n=43$ ) was mainly due to sample rejection at the onset of the study and Dengue IgM negative 18 in the Treatment group and only 8 in the Control group.

The sample rejection in the treatment group at the onset was due to some opinions given to them by their relatives due to the fear of mixing herbal drugs with western medicine. This decision was taken by these subjects after signing the consent form by going through the information sheet but clearly before starting to consume CPLE.

The data collection was conducted from June 2014 to February 2015. Recruitment was stopped after achieving the required simple size in both groups.

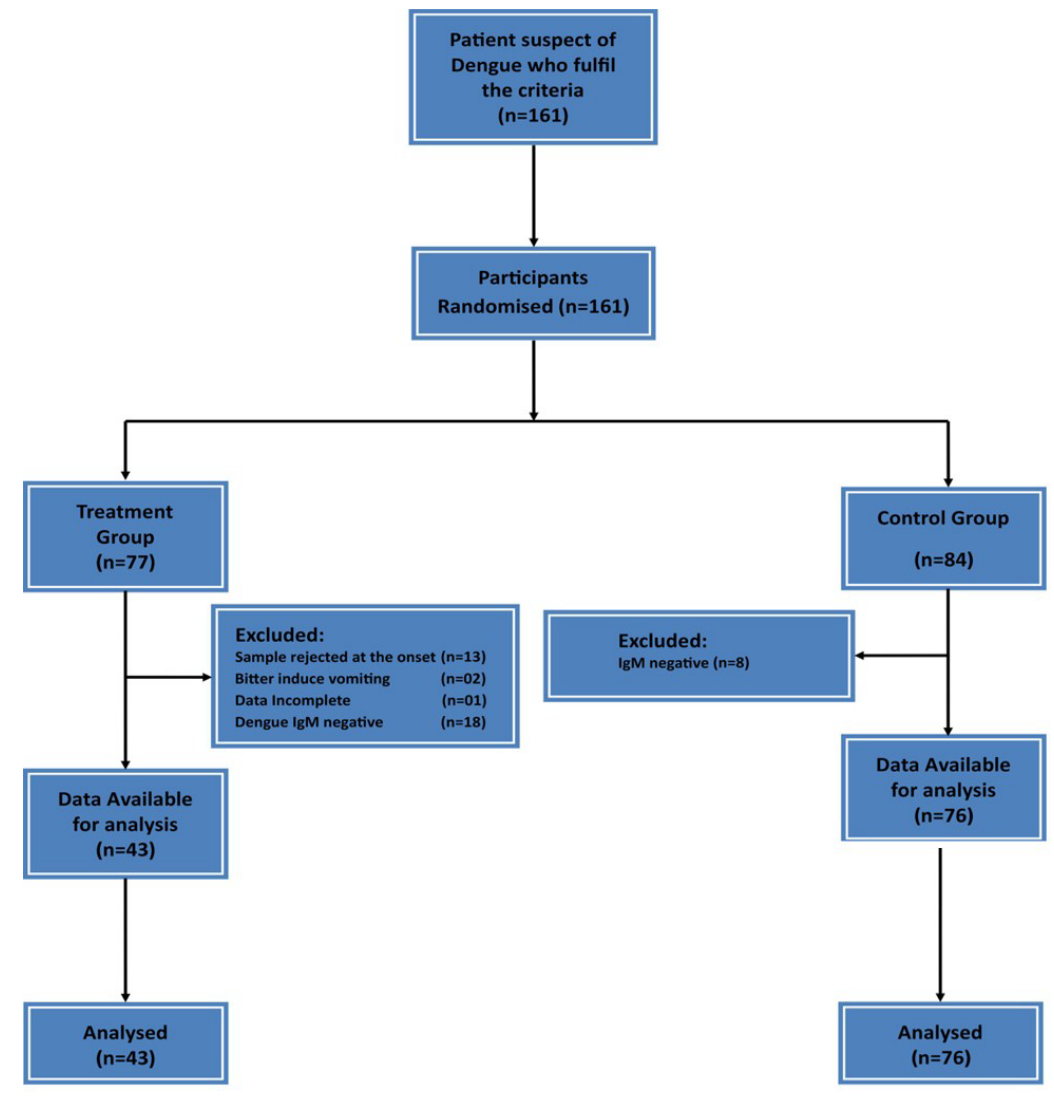

Figure 1: Flow Chart of Study design. 


\section{Age and Sex Distribution}

Both groups had almost equal age and sex distribution with a male predominance (Table 1).

\section{Condition of the Patients at the Time of Entry}

All the patients were in the febrile phase at the time of entry into the study. Means of number of days of fever on admission, systolic blood pressure, diastolic blood pressure, WBC, PLT and PCV counts were compared between treatment and control groups. Both groups had similar baseline values at entry to the study with no significant variation between both groups $(\mathrm{P}>0.05)$ (Table 2$)$.

The reason for these parameters to be same in both groups was due to the fact that both treatment and control groups were entered into the study early in the illness before onset of complications.

\section{Clinical Parameters}

Clinical parameters (total days of illness, duration of fever in the hospital, duration of hospital stay and incidence of pleural effusion) were considered in the analysis and Mann Whitney $\mathrm{U}$ test (Non parametric test) has been used to assess the significance (Table 3).

Table 1: Mean age \& Sex distribution among treatment and control groups.

\begin{tabular}{|c|c|c|c|c|}
\hline & & Mean Age & Standard deviation & Sex \\
\hline \multirow{2}{*}{ Male } & Treatment & 30.58 & 10.28 & $36(83.7 \%)$ \\
\hline & Control & 27.36 & 8.24 & $61(80.3 \%)$ \\
\hline \multirow{2}{*}{ Female } & Treatment & 29.43 & 7.34 & $7(16.3 \%)$ \\
\hline & Control & 26.60 & 7.93 & $15(19.7 \%)$ \\
\hline \multirow{2}{*}{ Total } & Treatment $n=43$ & 30.40 & 9.80 & $43(100 \%)$ \\
\hline & Control $\mathrm{n}=76$ & 27.21 & 8.13 & $76(100 \%)$ \\
\hline
\end{tabular}

Table 2: Comparison of Clinical \& Haematological parameters between Treatment and Control groups at the time of entry.

\begin{tabular}{|l|c|c|c|c|c|}
\hline \multirow{2}{*}{ Variable } & \multicolumn{2}{|c|}{ Treatment $\mathbf{n}=\mathbf{4 3}$} & \multicolumn{2}{|c|}{ Control $\mathbf{n = 7 6}$} & \multirow{2}{*}{ P value } \\
\cline { 2 - 6 } & Mean & $\begin{array}{c}\text { Standard } \\
\text { deviation }\end{array}$ & Mean & $\begin{array}{c}\text { Standard } \\
\text { deviation }\end{array}$ & \\
\hline Mean of No. of days of fever on admission & 4.558 & 0.958 & 4.224 & 1.30 & 0.157 \\
\hline Mean systolic blood pressure $(\mathrm{mmHg})$ & 107.419 & 13.477 & 105.947 & 17.114 & 0.900 \\
\hline Mean diastolic blood pressure $(\mathrm{mmHg})$ & 68.884 & 10.395 & 67.368 & 10.433 & 0.568 \\
\hline Mean white blood cell count $\left(10^{9} /\right.$ liter $)$ & 3.950 & 1.592 & 3.847 & 1.659 & 0.434 \\
\hline Mean platelet count $\left(10^{9} /\right.$ liter $)$ & 105.093 & 41.698 & 107.368 & 45.570 & 0.836 \\
\hline Mean packed cell volume $(\%)$ & 44.068 & 4.799 & 42.809 & 4.444 & 0.241 \\
\hline
\end{tabular}

Table 3: Comparison of Clinical \& Haematological parameters between Treatment and Control groups during the study.

\begin{tabular}{|l|l|l|l|l|l|}
\hline \multirow{2}{*}{ Variable } & \multicolumn{2}{|l|}{ Treatment $\mathbf{n}=\mathbf{4 3}$} & \multicolumn{2}{l|}{ Control $\mathbf{n}=\mathbf{6}$} & \multirow{2}{*}{ P value } \\
\cline { 2 - 6 } & Mean & $\begin{array}{l}\text { Standard } \\
\text { deviation }\end{array}$ & Mean & $\begin{array}{l}\text { Standard } \\
\text { deviation }\end{array}$ & \\
\hline $\begin{array}{l}\text { Mean of total days of illness/Onset of fever } \\
\text { to discharge }\end{array}$ & 6.512 & 1.05 & 6.961 & 1.32 & 0.029 \\
\hline Mean duration of fever in the hospital & 1.674 & 1.36 & 2.803 & 1.79 & 0.001 \\
\hline Mean duration of hospital stay & 3.698 & 1.08 & 4.474 & 1.40 & 0.001 \\
\hline Mean SGPT on $6^{\text {th }}$ day of illness $(\%)$ & 147.08 & 160.45 & 135.05 & 147.24 & 0.702 \\
\hline Mean SGOT on $6^{\text {th }}$ day of illness $\left(10^{9} /\right.$ liter $)$ & 195.90 & 209.99 & 187.74 & 148.35 & 0.245 \\
\hline $\begin{array}{l}\text { Mean white blood cells on } 6^{\text {th }} \text { day of illness } \\
\left(10^{9} / \text { liter }\right)\end{array}$ & 4.59 & 1.98 & 3.95 & 1.86 & 0.077 \\
\hline $\begin{array}{l}\text { Mean platelet count on } 6^{\text {th }} \text { day of illness } \\
\left(10^{9} / \text { liter }\right)\end{array}$ & 67.47 & 33.39 & 60.96 & 33.74 & 0.299 \\
\hline $\begin{array}{l}\text { Mean packed cell volume on } 6^{\text {th }} \text { day of } \\
\text { illness }(\%)\end{array}$ & 41.64 & 4.7 & 42.50 & 4.45 & 0.141 \\
\hline
\end{tabular}

Total duration of illness was taken as from onset of fever to discharge .The mean duration of illness is significant between treatment and control group $(\mathrm{p}<0.05)$. Mean total days of the illness in treatment group $6.51 \pm 0.05$ and in the control group $6.96 \pm 0.32$. It shows that mean total duration of the illness is reduced by $7.3 \%(0.5$ days) in the treatment group (Table 3 ).

Mean duration of fever in the hospital was $1.67 \pm 1.36$ and 2.80 \pm 1.79 in the treatment group and control group respectively and mean duration of hospital stay was $3.69 \pm 1.80$ and $4.47 \pm 1.40$ in the treatment and control groups respectively and are highly significant between treatment and control group $(\mathrm{p}<0.001)$. It also shows that duration of hospital stay is reduced by $21.3 \%$ (0.78days) and duration of fever is reduced by $57.1 \%$ ( 1.13 days) in the treatment group (Table 3).

\section{Clinically Evident Complications/Dengue Haemorrhagic Fever}

Both groups were screened for pleural effusions throughout the study by ultrasound scanning. Presence of pleural effusion indicates that the patient is in dengue haemorrhagic fever [26].

Only two (02) patients led to pleural effusion in treatment group and twelve (12) patients led to pleural effusion in control group (Proportion Normality test, $\mathrm{p}$ value 0.000 ). Hence development of pleural effusion/leading to dengue haemorrhagic fever is significantly lowers ( $p$ value $<0.05$ ) in treatment group when compared to control group (Table 4$)$.

All these patients developed pleural effusion after allocating to the study and all the 161 patients were free of pleural effusion at the entry to the study.

\section{Haematological Parameters}

Mean values of WBC, PLT and PCV were more favorable in the treatment group when compared to control group as shown graphically (Figures 2-4).

Highest difference was seen on the $6^{\text {th }}$ day of illness that is after 2 to 3 days of CPLE treatment. These differences in improvement were not statistically significant (Table 3 ).

\section{Biochemical Parameters}

There was no significant difference in the Mean SGOT and SGPT levels (U/L) on the $6^{\text {th }}$ day of illness between treatment and control groups. 195.90 vs. 187.74 and 147.08 vs. 135.05 in the treatment \& control groups respectively (Table 3 ). The mean values are high in both groups.

Table 4: Evidence of pleural effusion among treatment and control groups.

\begin{tabular}{|l|c|c|}
\hline & Treatment & Control \\
\hline Pleural effusion & $2(4.7 \%)$ & $12(15.8 \%)$ \\
\hline No pleural effusion & $41(95.3 \%)$ & $64(84.2 \%)$ \\
\hline Total & $43(100 \%)$ & $76(100 \%)$ \\
\hline
\end{tabular}




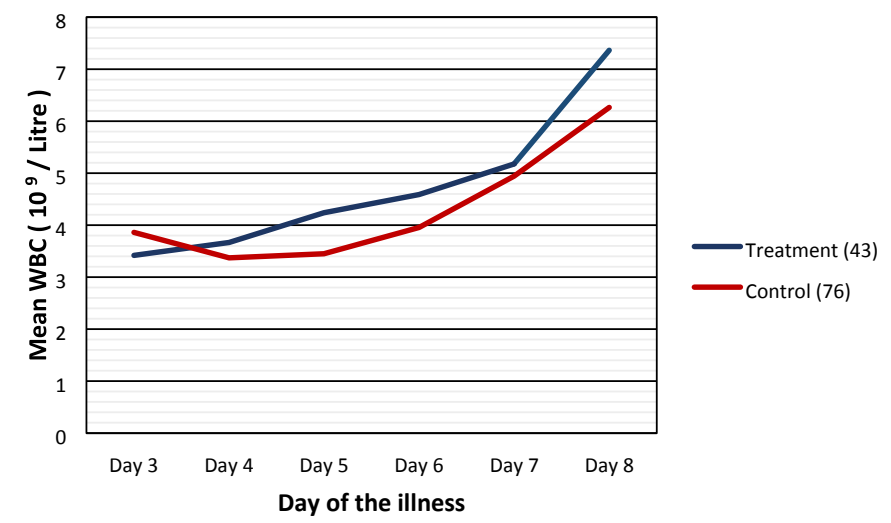

Figure 2: Comparison of mean white blood cells between treatment and control groups.

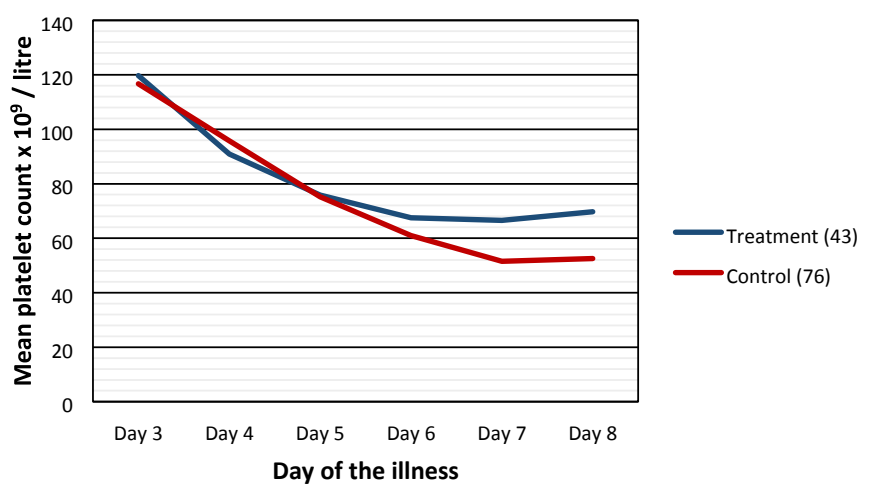

Figure 3: Comparison of mean platelets between treatment and control groups.

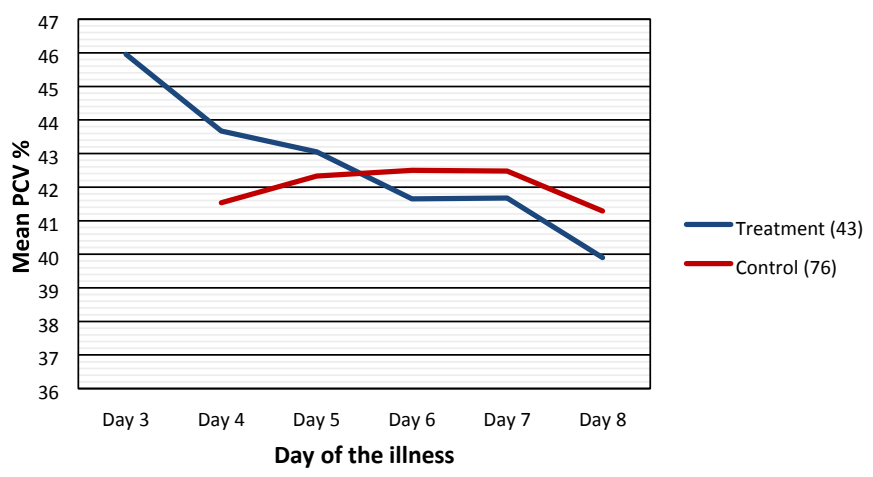

Figure 4: Comparison of mean packed cell volume/Hematocrit between treatment and control groups.

\section{Discussion}

\section{Summary}

This study have shown that CPLE is effective in improving clinical parameters of Dengue (Fever, Duration of illness, Hospital stay) and most importantly reduction in the incident of DHF in the Treatment Group. These clinical improvements were statistically significant (Table 3). Haematological Parameters (WBC, PLT, PCV) showed improvement in parallel to the clinical improvement though these differences were not statistically significant but they are clinically significant (Figures 2-4).

Haematological improvements were seen in the treatment group from the $5^{\text {th }}$ day of the illness CPLE had taken about 24 to 48 hours to exert its action on homological parameters.
We did not observe solitary increase in the PLT without the improvement of other clinical parameters (Figures 2-4).

\section{Strength \& Limitation}

Most other studies have looked only at PLT rising property of CPLE. This is the only study which have looked at other clinical parameters. Most clinicians were in the opinion that CPLE only had an effect on the PLT but this research have shown that it has other actions capable of improving clinical outcomes like fever duration of illnesses and reducing the incidence of complications like DHF.

The main limitation of the study was blinding and placebo control was not possible. Blinding was not possible; as we had to give freshly prepared pure CPLE to make sure that its constituents remain stable. It is not possible to make a placebo for CPLE and that is why we conducted the research as an open labelled study.

The study was also not large enough to show any differences in clinical complications like shock, haemorrhage etc. It would have been ideal if we could have looked at the effect of CPLE from day one of the illnesses at primary care level to complete clinical and biomedical recovery in hospital. Patients entered to this study on $2^{\text {nd }}, 3^{\text {rd }}$ and $4^{\text {th }}$ days of the illness and was discharged early before full biochemical improvement, to be managed by general practitioners in their home environment. Therefore we could only observe the effect of CPLE on a limited time period of the illness.

\section{Comparison with Existing Clinical Research}

Hettige $S$. in 2008 studied 12 consecutive Dengue patients treated with CPLE and showed that there was rapid increase in WBC, PLT and all patients recovered without hospital admission [6]. Following this study many clinical trials including RCT had shown similar results [7-24].

Otsuki N. and others in 2010 studied anti-tumor activity and immune-modulatory effects of CPLE [11]. This in-vitro study had shown that CPLE can enhance the Th1 type immunity. Research have shown that shift of DF to DHF is the result of the shift in the immune response of Th1 type immunity to Th2 type immunity [12]. According to the above research CPLE prevents the immune shift by reducing the incidence of DHF.

Norahmed N.A. and others have shown immuno-modulatory role of CPLE in Dengue virus infected rats [17-20]. Our study has demonstrated this effect clinically by reducing the incidence of DHF in the treatment group.

\section{Recommendation and Generalizability}

Studies have repeatedly shown potential benefit of CPLE in DF. In many Asian countries it's now being used as tablets and capsules for its PLT rising properties [21-24,28].

The most important property of therapeutic agent in dengue would be to prevent leakage of fluid and conversion of DF to DHF. This study has shown that CPLE may have above mentioned therapeutic properties in addition to the improvement of other clinical parameters. 
Therefore we recommend a placebo controlled similar study with a larger sample size and observe the therapeutic effects from day one of the illness to full biochemical and haematological normalization (e.g. Till the PLT reach $250-300 \times 10^{9} /$ liter).

\section{Abbreviations}

CPLE: Carica papaya leaf extract

DF: Dengue Fever

RCT: Randomized Controlled clinical Trials

DHF: Dengue haemorrhagic fever

WBC: White cell count

PCV: Packed cell volume

PLT: Platelet count

SGPT: Alanine transaminase

SGOT: Aspartate transaminase

\section{Declarations}

\section{Ethics Approval}

Ethical approval had been obtained from Ethical approval committee of Faculty of Medical sciences University of Sri Jayewardenepura and also registered in the Sri Lanka Clinical Trial Registry SLCTR/2013/005 and World Health Organization International Clinical Trials Registry Platform.

Special approval also had been taken from the Sub Committee on Clinical Trials of Ministry of Health, Sri Lanka as this study was conducted in a tertiary care hospital in Sri Lanka.

\section{Consent to Participate \& Publication}

Written consent had been obtained from all participants before they were entered to the research.

\section{Data Sharing Statement}

All the data collected are analysed and presented in this document.

The datasets used \& analysed during the current study are available from the corresponding author on reasonable request.

We are willing to share the data that we have collected and presented in this article for interested parties in Dryad repository if required.

\section{Competing Interests}

None declared by the authors.

\section{Funding}

Self-Funded.

\section{References}

1. World Health Organization, Dengue and severe dengue. http://www.who.int/ mediacentre/factsheets/fs117/en/, updated May 2015, Accessed 23 September 2019.

2. NDTV Here's How Papaya Leaf Juice Can Be Used to Treat Dengue and Malaria:
As Suggested by Luke Coutinho. https://www.ndtv.com/health/denguepapaya-leafjuice-heres-a-simpleway-to-boost-your-platelet-count-naturally2066099 updated July 2019, Accessed 23 September 2019.

3. Sarala N, Paknikar SS (2014) Papaya Extract to Treat Dengue: A Novel Therapeutic Option. Ann Med Health Sci Res. 4(3): 320-324. [crossref]

4. Carica papaya, http://en.wikipedia.org/wiki/Carica_papaya, Wikipedia free encyclopedia, updated: on 26 July 2012, Accessed 16 August 2019.

5. WHFoods, papaya, http://www.whfoods.com/genpage.php?tname=foodspice\&dbid=47, www.WHfoods.org, Accessed 16 August 2019.

6. Hettige S (2008) Salutary Effects of Carica papaya in dengue fever patients, Sri Lanka Family Physician, 2008 Vol. 29, PP. 17-19. Accepted by WHO http://apps.who.int/ trialsearch/Trial2.aspx?TrialID=SLCTR/2013/005

7. Hettige S (2019) Dengue: an escalating problem. BMJ 2002, http://www.bmj.com/ rapid-response/2011/11/03/repapaya-leavesspeedyrise-platelet-count-dengue, published 29 June 2002, Accessed 16 August 2019

8. Hettige S (2015) 'Guidelines in using carica papaya leaf extract for Dengue fever patients', BMJ Clinical Review (BMJ 2015;351:h4661), pp. [Online]. Available at: https://www.bmj.com/content/351/bmj.h4661/rr-4 (Accessed: 22ng October 2019).

9. Hettige S (2016) Carica papaya leaf extract in Dengue fever. IMPA Journal|December 2015|Volume 09|Number 01, IMPA Journal; pg. 11-14. [Internet]. 2016 [cited 24February2016]; Available from:https://www.dropbox. com/s/b8zejo8r7nx3l6e/09\%20Impa\%20Journal\%20 -\%20volume\%2009.pdf?dl=0 (Accessed: 22ng October 2019).

10. Subenthiran, S, Choon TC, Cheong KC, et al. (2013) Carica papaya leaves Juice significantly accelerates the rate of increase in platelet count among patients with Dengue fever and Dengue haemorrhagic fever. Evidence based complementary and alternative Medicine. 2013 (ID616737), p: 7. [crossref]

11. Otsuki, N, Dang NH, Kumagai E, et al. (2010) Aqueous extract of carica papaya leaves exhibits anti-tumor activity and immunomodulatory effects. Journal of Ethnopharmacology. 127, p760-767. [crossref]

12. Chaturvedi U, Agarwal R, Elbishbishi E (2000) Cytokine cascade in dengue hemorrhagic fever: implications for pathogenesis. 1st ed. [ebook] Elsevier Science BV, FEMS Immunology \& Medical Microbiology, pp. 28. [crossref]

13. Ranasinghe P, Ranasinghe P, Abesekara WPKM, et al. (2011) In-vitro erythrocyte membrane stabilization properties of carica papaya L. leaf extracts. 3rd international conference on medicinal plants and herbal medicines. Colombo, Sri Lanka.

14. Imaga NOA, Gbenle GO, Okochi VI, et al. (2009) Anitisicking property of carica papaya leaf extract. African Journal of Biochemistry Research. 3 (4), p102-106.

15. Senthilvel P, Lavanya P, Kumar KM, et al. (2013) Flavonoid from Carica papaya inhibits ns 2 bnS3 protease and prevents Dengue 2 viral assembly. Bioinformation. 9(18): 889-895. [crossref]

16. Pangtey GS, Prakash A, Munjal YP (2016) Role of Carica papaya leaf extract for Dengue associated Thrombocytopenia. Journal of the association of physicians of India. 2016, [Online] Available at: http://www.japi.org/june_2016/01_Editorial_role of_carica.pdf Accessed 14 September 2019 [crossref]

17. Norahmad NA, Razak MRMA, Misnan NM, et al. (2019) The effect of freeze dried Carica papaya leaf juice on inflammatory cytokine production during dengue virus infection in AG129 mice. BMC Complementary and Alternative Medicine. 19: 44 [crossref]

18. Sathasivam K, Ramanathan S, Mansor SM, et al. (2009) Thrombocyte counts in mice after the administration of papaya leaf suspension. WienKlinWochenschr-The middle European Journal of Medicine. 121 (3), p19-22.

19. Hettiarachchi K (2012) Guinea pig rats fed papaya leaf juice concentrate show intriguing results - Tests recording platelet count rise may give hope for dengue patients. Sunday Times

20. Halim SZ, Abdullah NR, Afzan A, et al. (2011) Study of acute toxicity of Carica papaya leaf extract in sprague dawley rats. Journal of Medicinal Plants Research. 5 (2), p1867-1872.

21. Kasture PN, Nagabhushan KH, Kumar A (2016) A multi centric double blind placebo controlled randomized prospective study to evaluate the efficacy and safety of carica papaya leaf extract as empirical therapy for thrombocytopenia associated with Dengue fever. Journal of the association of physicians of India. [crossref] 
22. Gadhwal AK, Ankit BS, Chahar C, et al. (2016) Effect of Carica papaya leaf extract capsule on platelet count in patients of dengue fever with Thrombocytopenia. Journal of the Association of Physicians of India [Online] Available at: http://www.japi.org/ june_2016/03_oa_effect_of_carica.pdf Accessed 14 September 2019

23. Hettige $S$ (2017) 'The use of dried carica papaya leaf capsules in dengue fever patients in the recent dengue epidemic in June - August 2017', Sri Lankan Family Physician, Vol. 33 No. 1(ISSN 1391-1961), pp. 21-26 [Online]. Available at: http://cgpsl.org/ wpcontent/uploads/2018/01/SLFP-October-2017PDF1.pdf (Accessed: 15th October 2019).

24. Srikrishna HA, et al. (2018) Clinical Evaluation for the Thrombopoietic Activity of Platenza Tablet in Cases of Dengue with Thrombocytopenia - Randomized Open Label Comparative Clinical Study. Ann Med Health Sci Res. 8: 29-38.
25. Kalayanarooj S. Clinical Manifestations and Management of Dengue/DHF/DSS. Tropical Medicine and Health 2011, http://www.ncbi.nlm.nih.gov/pmc/articles/ PMC3317599/, published 22 Dec 2011, Accessed 16 August 2019. [crossref]

26. Ministry of Health - Sri Lanka. Guidelines on Management of Dengue Fever \& Dengue Haemorrhagic Fever InAdults.http://www.epid.gov.lk/web/images/pdf/Publication/guidelines_for_the_ma nagement_of_df_and_dhf_in_adults.pdf Accessed 16 August 2019.

27. Conroy R. Sample size a rough guide: sample sizes and powers for comparing two means where the variable is measured on a continuous scale that is (more or less) normally distributed: $13-15$.

28. Medline Plus, platelet count, http://www.nlm.nih.gov/medlineplus/ency/article/003647.htm, updated 02 February 2013, Accessed 16 August 2019. 